\title{
Perfil de competencias digitales en alumnos universitarios e influencia por el confinamiento COVID-19
}

\begin{abstract}
Marta Ingelmo Palomares ${ }^{a}$, José Ángel Sanz Lara ${ }^{b}$, Ana Bedate Centeno ${ }^{c}$, Sara Pinillos-Franco ${ }^{d}$
a Departamento de Organización de Empresas y Comercialización e Investigación de Mercados. Universidad de Valladolid. Plaza del Campus Universitario 1, 47011 Valladolid. marta@emp.uva.es ${ }^{\text {b }}$ Departamento de Economía Financiera y Contabilidad. Universidad de Valladolid. Plaza del Campus Universitario 1, 47011 Valladolid. angel@emp.uva.es ${ }^{c}$ Departamento de Economía Financiera y Contabilidad. Universidad de Valladolid. Plaza del Campus Universitario 1, 47011 Valladolid. ana@emp.uva.es d Departamento de Análisis Económico: Teoría Económica e Historia Económica. Universidad Autónoma de Madrid. Calle Francisco Tomás y Valiente, 5, 28049 Madrid. sara.pinillos@uam.es.
\end{abstract}

\section{\$EWWFW}

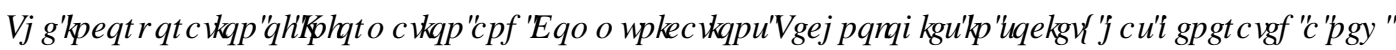

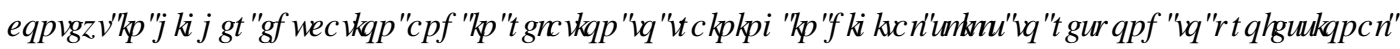

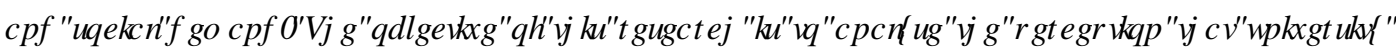

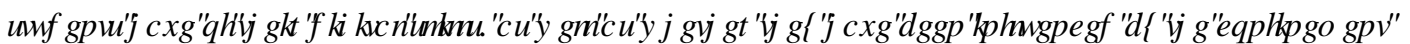

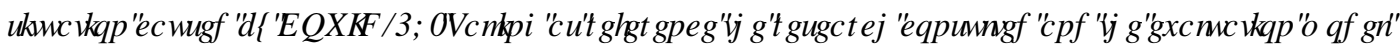

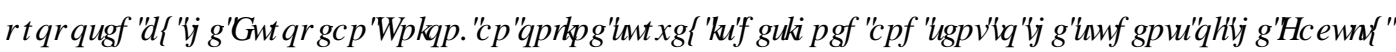

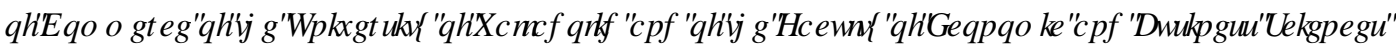
RIIKHL\$ XURQRP RXVB QYYHUWMRIDO DOUGD

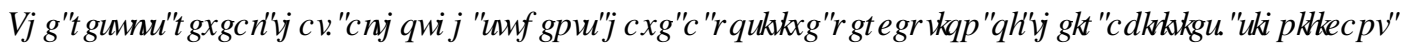

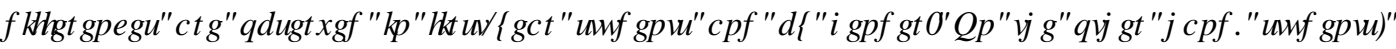



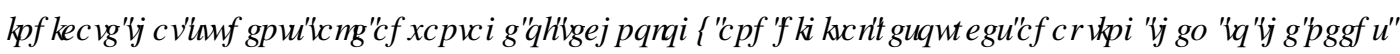
$R I L H F K P R P$ HQW

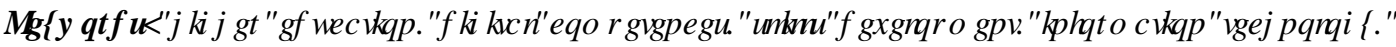

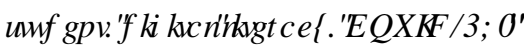

[

\section{HXP HQ]}

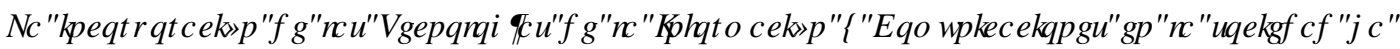

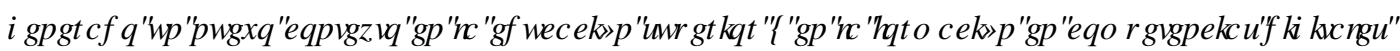

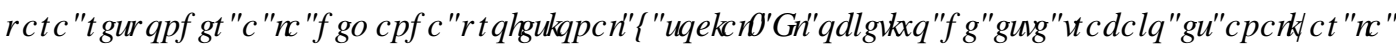

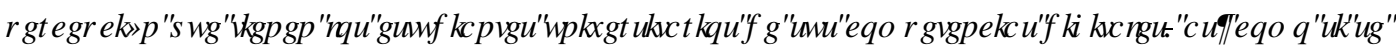

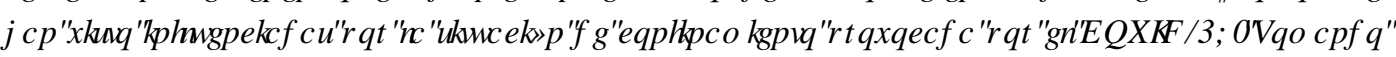

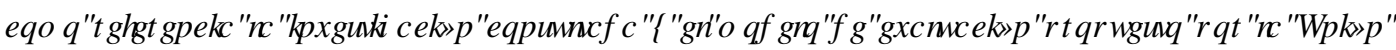

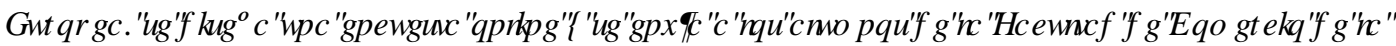

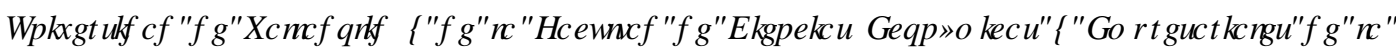
8 QVYHUGDG\$ XWYRP DIGHO DOUGD

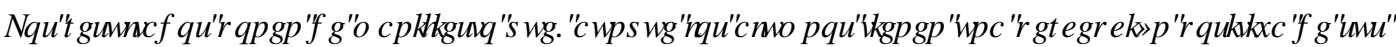

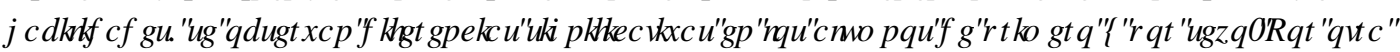

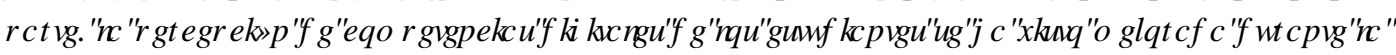




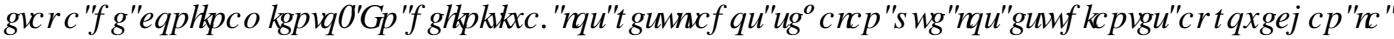



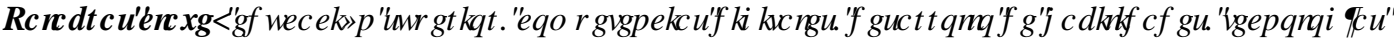

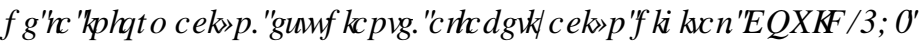

\section{Introducción}

La incorporación de las Tecnologías de la Información y Comunicaciones (TIC) dentro de la sociedad ha cambiado completamente la percepción del aprendizaje y de la comunicación. No se entiende el día a día de nuestra vida sin el uso de las tecnologías. Estamos en una nueva era con grandes posibilidades, la era de la Sociedad de la Información. Las instituciones internacionales son conscientes de estos cambios, así la Cumbre Mundial sobre la Sociedad de la Información (Ginebra, 2003 y Túnez, 2005) declaró el deseo y compromiso de construir una Sociedad de la Información. Sociedad en la que es posible generar, intercambiar, compartir y comunicar información y conocimiento entre todas las redes del mundo (Lion, 2013). El 18 de diciembre de 2006, el Parlamento Europeo y el Consejo de la Unión Europea publicaron una recomendación sobre las competencias clave para el aprendizaje a lo largo de toda la vida. En ella se identificaron y definieron ocho competencias clave ${ }^{1}$ que se deben proporcionar a través del aprendizaje a lo largo de la vida, como una medida clave en la respuesta de Europa a la globalización y al cambio basado en el conocimiento de la sociedad. La habilidad digital es considerada una competencia clave, necesaria para el desarrollo personal, la ciudanía activa y el empleo de todos los individuos (Kiss, 2017). Las competencias clave son las que todos los individuos necesitan para su realización y desarrollo personal, la ciudadanía activa, la inclusión social y el empleo.

Por tanto, la competencia digital no solo proporciona la capacidad de aprovechar las posibilidades asociadas a las tecnologías digitales, sino que es necesaria para participar en la nueva sociedad y economía del conocimiento del siglo XXI. La European Commission (2019a) afirma que los estudiantes de todas las edades necesitan la competencia digital para poder beneficiarse de las nuevas posibilidades que ofrece la tecnología aumentando la motivación, la eficacia y la inclusión en el proceso de aprendizaje.

Por otra parte, la implantación del Espacio Europeo de Educación Superior (EEES), ha generado un nuevo contexto en la educación superior siendo uno de sus objetivos «formular criterios académicos, competenciales y de cualificación profesional que respondan a la demanda del mercado laboral europeo y que permitan responder a los retos educativo, laborales y sociales actuales» (García y Pérez, 2008, p.2).

En este entorno el alumno debe adquirir tanto las capacidades necesarias para realizar sus actividades de aprendizaje, como las que posteriormente se le exigirán en el mercado laboral (Martínez, 2009; Dede, 2010; SCOPEO, 2011; Burton, 2019).

Nuestra investigación está diseñada para analizar la percepción que tienen de las competencias digitales los estudiantes universitarios de la Facultad de Comercio de la Universidad de Valladolid y de la Facultad de Ciencias Económicas y Empresariales de la Universidad Autónoma de Madrid y cómo ha influido en ellas la situación de confinamiento provocada por el COVID-19, con la intención de detectar señales que ayuden a identificar la situación actual y nos dé una pista en el diseño de estrategias futuras. El trabajo presenta la siguiente estructura: en primer lugar, se expondrán los objetivos que se pretenden alcanzar con este artículo,

\footnotetext{
${ }^{1}$ Las competencias clave que se identificaron fueron la comunicación en la lengua materna, la comunicación en lenguas extranjeras, la competencia matemática y competencias básicas en ciencia y tecnología, la competencia digital, aprender a aprender, las competencias sociales y cívicas, el sentido de la iniciativa y espíritu de empresa, y la conciencia y expresión culturales.
} 
seguidamente se detalla el desarrollo de la innovación explicando la metodología utilizada para realizar la investigación, a continuación, se presentan los resultados obtenidos, y finalmente se plantean las conclusiones y limitaciones del estudio.

\section{Objetivos}

Con esta investigación se busca un doble objetivo: en primer lugar, conocer la influencia que ha tenido la situación del confinamiento provocada por la pandemia COVID-19 en la valoración de las competencias digitales de los estudiantes universitarios; y en segundo lugar, determinar el valor que asignan a las competencias digitales los estudiantes universitarios de la Facultad de Comercio (Valladolid) y de los alumnos de primer curso de la Facultad de Ciencias Económicas y Empresariales de la Universidad Autónoma de Madrid. Además, se analiza si existen diferencias en las valoraciones del uso de las TIC en función de que los estudiantes sean o no de primer curso de universidad y del sexo. La intención es detectar posibles deficiencias que se puedan mejorar enfocando el aprendizaje de nuestros alumnos con el fin de cubrir las necesidades generadas por la era de la digitalización. De hecho, el estudio revela que nuestros estudiantes deben mejorar sus competencias en tratamiento de imagen o video digital, así como en materia de seguridad.

\section{Desarrollo de la innovación}

Para llevar a cabo nuestra investigación, la autoevaluación se ha realizado a través de un cuestionario, siendo la metodología más común en este tipo de investigación (Gui y Argentin, 2011). En 2011, la Comisión Europea desarrolla el proyecto "Marco Europeo de Competencias Digitales para los Ciudadanos (DigComp)" para elaborar un marco de referencia de Competencia Digital, con el objetivo de producir los descriptores de competencia digital para todos los niveles de learners y así conocer el nivel de las habilidades digitales de los europeos. Los indicadores utilizados en este trabajo para medir la percepción de los alumnos en su nivel de competencias digitales se han tomado de la versión actualizada del marco conceptual DigComp (European Commission, 2019b), y del estudio realizado por Torres-Coronas y VidalBlasco (2015).

La competencia digital, incluye tipos de habilidades muy variadas, pudiendo mostrar valoraciones muy distintas en cada una de ellas. Por eso el cuestionario se ha agrupado en seis bloques (Competencias genéricas antes y durante el COVID-19; Alfabetización tecnológica; Comunicación y colaboración; Acceso y uso de la información; Seguridad y Ciudadanía digital; y Creatividad e innovación). Se pidió a los alumnos que valoren de menor a mayor (escala Likert de 1 a 5) su nivel de dominio en una serie de competencias muy diferenciadas, dentro de cada uno de esos bloques. En el primer bloque el alumno valoraba tanto sus competencias antes del COVID-19 como durante el COVID-19. Por otra parte, se incluyeron preguntas para conocer el tiempo de uso de ordenador y la valoración del nivel de formación recibido en TICs, así como el curso en el que están matriculados, la edad y el sexo.

El cuestionario se diseñó y envió online a través de Google Drive a todos los estudiantes matriculados en la Facultad de Comercio de la Universidad de Valladolid (Grado en Comercio, Máster en Comercio Exterior, Máster en Relaciones Internacionales y Estudios Asiáticos, Máster en Economía de la Cultura y Gestión Cultural) y a los estudiantes de primer curso matriculados en el Grado en Administración y Dirección de Empresas y en el Grado en Turismo de la Facultad de Ciencias Económicas y Empresariales de la Universidad Autónoma de Madrid. El cuestionario estuvo disponible para ser rellanado desde el 1 de marzo de 2021 hasta el 14 de marzo de 2021. 
Se obtuvo un total de 348 respuestas válidas, creando una muestra en la que el 48,28\% son hombres y el 51,72\% mujeres, el 11,21\% estudian en la Universidad Autónoma de Madrid y el 88,79\% en la Universidad de Valladolid, el 35,55\% está cursando primero, el 18,21\% segundo, el 31,21\% tercero, el 7,23\% está en último curso de carrera, mientras que el 7,80\% está realizando un máster. En cuanto a la edad, el 38,30\% tendrán en 202119 o 20 años, el 27,78\% tendrán 21 o 22 años, el 18,72\% 23 o 24, el 8,77\% 25 o 26 y el $6,43 \% 27$ o más años (Ver Tabla 1).

\begin{tabular}{ccc}
\hline Género & n & $\mathbf{\%}$ \\
\hline Hombre & 168 & 48,28 \\
Mujer & 180 & 51,72 \\
& & \\
\hline Universidad & $\mathrm{n}$ & $\mathbf{\%}$ \\
\hline Auton. Mad & 39 & 11,21 \\
Valladolid & 309 & 88,79 \\
\hline
\end{tabular}

\section{DECII 13 HUIOCHLRVHQXXHMDRV}

\begin{tabular}{ccc}
\hline Curso & n & \% \\
\hline Primero & 123 & 35,55 \\
Segundo & 63 & 18,21 \\
Tercero & 108 & 31,21 \\
Cuarto & 25 & 7,23 \\
Máster & 27 & 7,80 \\
\hline
\end{tabular}

\begin{tabular}{ccc}
\hline Años & n & \% \\
\hline $19-20$ & 131 & 38,30 \\
$21-22$ & 95 & 27,78 \\
$23-24$ & 64 & 18,72 \\
$25-26$ & 30 & 8,77 \\
27 o más & 22 & 6,43 \\
\hline
\end{tabular}

Por otra parte, se observa que el 38,51\% de los encuestados pasan más de tres horas al día en el ordenador (Fig. 1), el 25,36\% ha realizado algún curso online en competencias digitales (Fig. 2), y el 90,52\% consideran importante o muy importante el uso de la tecnología digital para mejorar la calidad profesional (valores 4 y 5 de la Fig. 3).

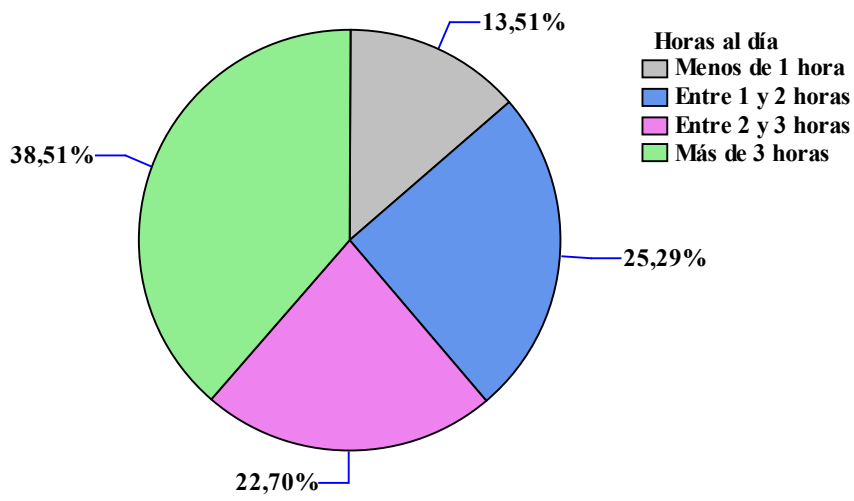

) $L \amalg \amalg+R U V D O A D T X H M H X W D O R L C H D O R U$

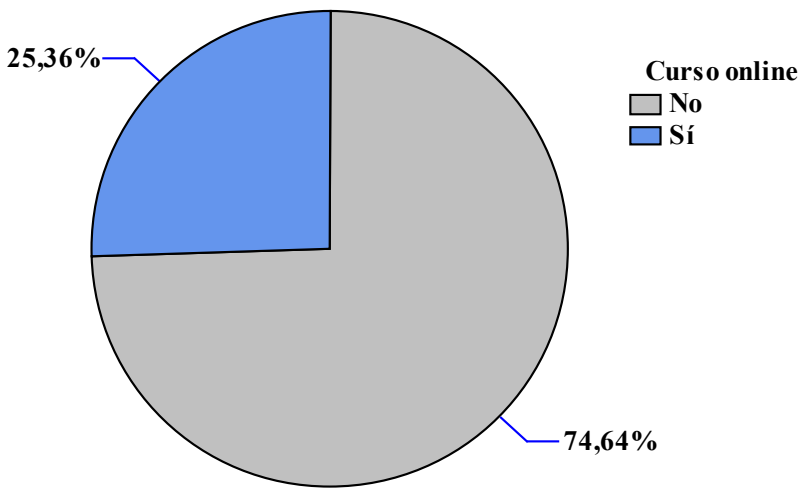

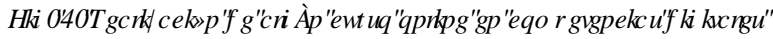




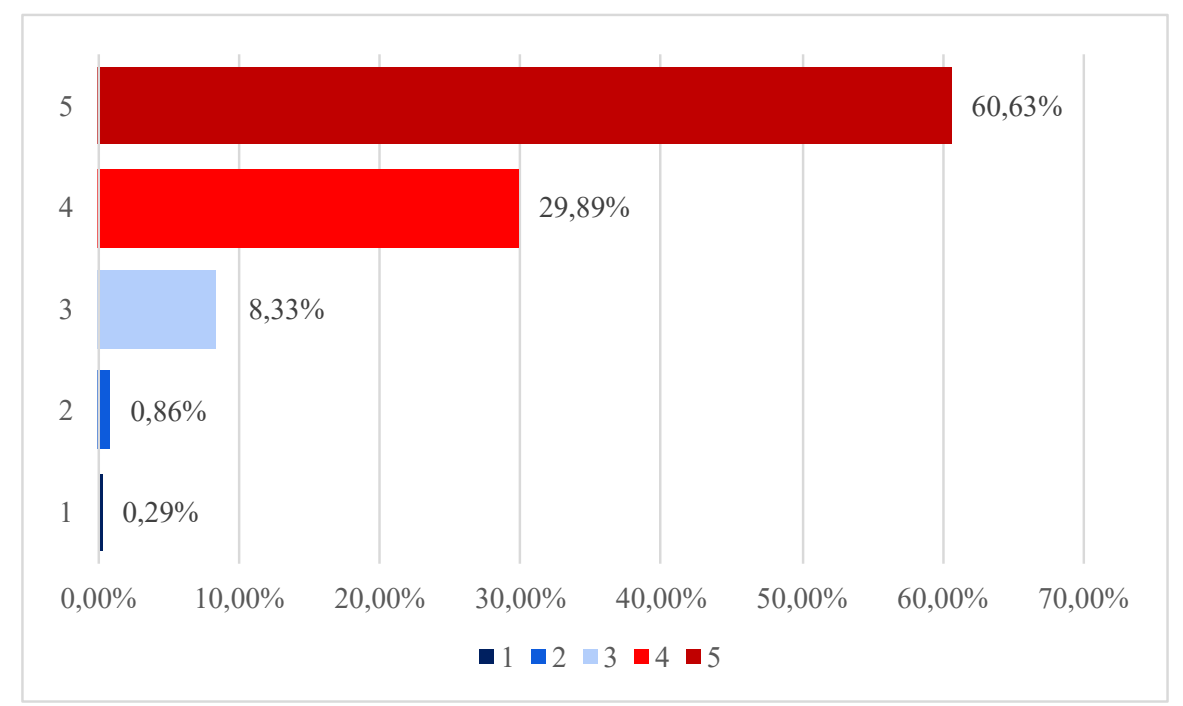

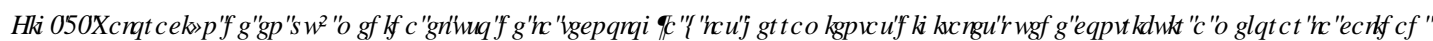
SLRIHRQDO

\section{Resultados}

Los resultados muestran que tanto antes, como durante el confinamiento provocado por la pandemia del COVID-19, la competencia genérica que más valoran los estudiantes es la "Búsqueda de información online" (4,00 y 4,16 respectivamente), mientras que la menos valorada es "Ejecuto y actualizo programas de seguridad en mis dispositivos" (2,88 y 3,20 respectivamente) (Ver Tabla 2). Los participantes en el estudio perciben que sus competencias digitales genéricas han mejorado durante el COVID-19. Esto se observa de forma gráfica en el incremento de las valoraciones más altas (4 y 5), marcadas en tonos rojos, durante el COVID-19, en todos los ítems analizados (Fig. 4).

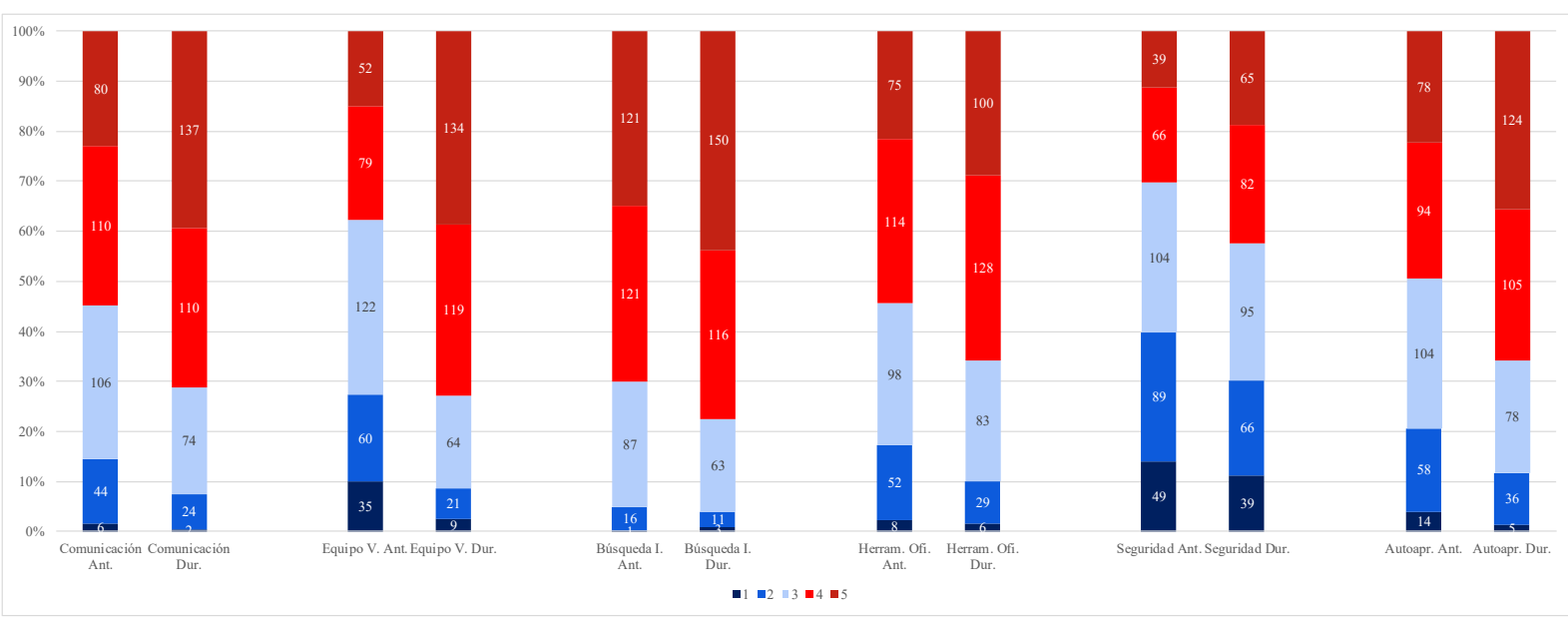

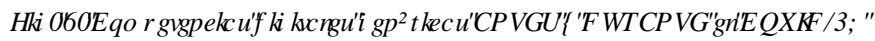


La Tabla 2 recoge los valores de la media, la desviación típica y el coeficiente de variación de Pearson que se emplearán para el análisis descriptivo. Examinando los resultados por bloques temáticos de competencias, en el aspecto de Alfabetización tecnológica, la percepción más elevada se alcanza en "Utilizo herramientas ofimáticas" $(4,04)$ mientras que las de menor puntuación fueron "Utilizo varios tipos de sistemas operativos instalados en un ordenador" $(2,73)$ y "Utilizo software de tratamiento de imagen, audio o video digital" $(2,86)$. Estos datos sacan a la luz dos cuestiones, por una parte, reafirman la utilidad de las asignaturas de informática en las que se trabajan herramientas ofimáticas, así como la de las diferentes materias en las que se aplica la ofimática en las clases prácticas. Por otra parte, los datos alertan de bajas competencias en el tratamiento de imagen, diseño y videos, circunstancia que puede reflejar la falta de asignaturas en las que se trabajen estas competencias. Además, esta carencia ha sido señalada desde el ámbito empresarial, donde nuestros alumnos realizan prácticas y han necesitado de esta habilidad. Será necesario por tanto adoptar alguna medida para adaptar a nuestros alumnos a las demandas del mercado, donde cada vez son más necesarias habilidades de este tipo en distintos trabajos relacionados con el ámbito empresarial, en los que antes no lo eran.

En el caso del bloque de Comunicación y colaboración, las mayores puntuaciones se corresponden con la "Utilización de herramientas de comunicación online" en sus dos versiones: chats, Skype, mensajes cortos; y blogs, foros, redes sociales $(4,37$ y 4,5 respectivamente) mientras que "Crear y dinamizar redes y comunidades profesionales" es la competencia con la media más baja $(2,62)$. Las habilidades de comunicación online forman parte de su día a día a nivel personal. En cambio, la mayoría de los alumnos todavía no están familiarizados con la creación y dinamización de redes profesionales, posiblemente porque todavía no han tenido esa necesidad.

Cuando examinamos las competencias de Acceso y uso de la información, "Organizo, analizo y uso la información a partir de herramientas digitales de forma efectiva" $(3,96)$ y "Localizo información relevante" $(3,91)$ son las que obtienen la nota más elevada, por el contrario, "Hacer referencia al utilizar contenidos protegidos por copyright" es la menos valorada $(2,92)$. A lo largo de la carrera y en la enseñanza previa a la universidad, los estudiantes están acostumbrados a realizar trabajos en los que requieren de búsqueda y análisis de información pertinente, de ahí que muestren alta capacitación. Pero, en general, es en los últimos cursos y más en concreto en la realización del Trabajo Fin de Grado, cuando se les exige de modo formal y obligatorio, citar correctamente las fuentes de la información utilizada.

Al hablar de Seguridad y Ciudadanía digital, se observa que la mayoría de los estudiantes son "Conscientes de que su paso por la web deja un rastro digital", pero la media 3,58 (en una escala de 1 a 5) deja ver que hay campo por mejorar en aspectos como por ejemplo la seguridad o la implicación a nivel profesional. Dentro del bloque Creatividad e innovación, la capacidad más dominada es la de "Adaptarse a nuevas situaciones y entornos tecnológicos" $(4,03)$ y la menos controlada es "Desarrollar iniciativas con espíritu emprendedor en el uso de las TIC" $(2,89)$. Los estudiantes son conscientes de que las tecnologías y el uso de las mismas están en constante cambio y están habituados a probar y aprender a utilizar programas y herramientas nuevas, en su día a día y en las aulas, aunque no se sienten capacitados para utilizarlas con espíritu emprendedor.

Las capacidades mejor valoradas tienen las medias más representativas, pues su coeficiente de variación de Pearson es inferior a 0,25, salvo en el caso de las competencias de Seguridad y Ciudadanía digital que es de 0,32 donde la media es un poco menos representativa. Esto quiere decir que en estas competencias la dispersión es baja y los valores otorgados se agrupan entorno a la media. Por el contrario, las valoraciones más bajas presentan una dispersión más elevada, es decir, están más alejadas de la media. 
Tabla 2. Medias, desviaciones estándar (DE) y coeficientes de variación de Pearson (CV) de las competencias antes y después del COVID-19y de las competencias evaluadas

\begin{tabular}{|c|c|c|c|}
\hline Tecnologías digitales antes y durante el COVID-19 & Media & DE & $\mathbf{C V}$ \\
\hline $\begin{array}{l}\text { El uso de la tecnología y herramientas digitales ha mejorado tu día a día } \\
\text { ANTES del periodo del confinamiento }\end{array}$ & 3,43 & 0,91 & 0,27 \\
\hline $\begin{array}{c}\text { El uso de la tecnología y herramientas digitales ha mejorado tu día a día } \\
\text { DURANTE el periodo del confinamiento }\end{array}$ & 4,25 & 0,88 & 0,21 \\
\hline Competencias genéricas antes del COVID-19 & Media & DE & $\mathbf{C V}$ \\
\hline Comunicación & 3,62 & 1,03 & 0,28 \\
\hline Trabajo en equipo virtual & 3,15 & 1,18 & 0,37 \\
\hline Búsqueda de información online & 4,00 & 0,90 & 0,23 \\
\hline $\begin{array}{l}\text { Herramientas ofimáticas (Excel, Word, ppt,...) para tratar la } \\
\text { información }\end{array}$ & 3,56 & 1,06 & 0,30 \\
\hline Ejecuto y actualizo programas de seguridad en mis dispositivos & 2,88 & 1,20 & 0,42 \\
\hline Autoaprendizaje & 3,47 & 1,13 & 0,33 \\
\hline Competencias genéricas durante el COVID-19 & Media & $\mathbf{D E}$ & $\mathbf{C V}$ \\
\hline Comunicación & 4,03 & 0,97 & 0,24 \\
\hline Trabajo en equipo virtual & 4,00 & 1,02 & 0,26 \\
\hline Búsqueda de información online & 4,16 & 0,90 & 0,22 \\
\hline $\begin{array}{l}\text { Herramientas ofimáticas (Excel, Word, ppt,...) para tratar la } \\
\text { información }\end{array}$ & 3,83 & 1,00 & 0,26 \\
\hline Ejecuto y actualizo programas de seguridad en mis dispositivos & 3,20 & 1,26 & 0,39 \\
\hline Autoaprendizaje & 3,88 & 1,06 & 0,27 \\
\hline Alfabetización tecnológica & Media & DE & $\mathbf{C V}$ \\
\hline $\begin{array}{l}\text { Utilizo varios tipos de sistemas operativos instalados en un ordenador } \\
\text { (Windows, Linux, MacOs, etc.) }\end{array}$ & 2,73 & 1,32 & 0,48 \\
\hline $\begin{array}{l}\text { Utilizo varios tipos de sistemas operativos instalados en dispositivos } \\
\text { móviles (Android, IOS, etc.) }\end{array}$ & 3,33 & 1,36 & 0,41 \\
\hline $\begin{array}{l}\text { Utilizo distintas herramientas ofimáticas para el tratamiento de la } \\
\text { información (Excel, Word, etc.) }\end{array}$ & 4,04 & 0,88 & 0,22 \\
\hline Utilizo software de tratamiento de imagen, audio o video digital & 2,86 & 1,24 & 0,43 \\
\hline Comunicación y colaboración & Media & DE & $\mathbf{C V}$ \\
\hline $\begin{array}{l}\text { Utilizo herramientas de comunicación online como chats, Skype, } \\
\text { mensajes cortos, etc. }\end{array}$ & 4,37 & 0,88 & 0,20 \\
\hline $\begin{array}{l}\text { Utilizo herramientas de comunicación online como blogs, foros, redes } \\
\text { sociales, etc. }\end{array}$ & 4,15 & 1,02 & 0,25 \\
\hline $\begin{array}{l}\text { Utilizo herramientas de colaboración con otras personas creando y } \\
\text { gestionando contenidos como calendarios electrónicos, sistemas de } \\
\text { gestión de proyectos, Dropbox, One Drive, Google Drive, etc. }\end{array}$ & 3,52 & 1,18 & 0,33 \\
\hline $\begin{array}{l}\text { Utilizo recursos en línea como Slideshare, Youtube, Flyckr, Google } \\
\text { Video, etc., para compartir y publicar online conocimientos con otras } \\
\text { personas }\end{array}$ & 3,16 & 1,38 & 0,44 \\
\hline $\begin{array}{l}\text { Creo equipos de trabajo multidisciplinares para el desarrollo de proyectos } \\
\text { o la resolución de problemas }\end{array}$ & 2,73 & 1,24 & 0,46 \\
\hline $\begin{array}{l}\text { Creo y dinamizo redes y comunidades profesionales del conocimiento } \\
\text { para el trabajo colaborativo en entornos virtuales }\end{array}$ & 2,62 & 1,23 & 0,47 \\
\hline Acceso y uso de la información & Media & DE & $\mathrm{CV}$ \\
\hline $\begin{array}{l}\text { Localizo información relevante a través de diferentes fuentes y bases de } \\
\text { datos disponibles en la Red }\end{array}$ & 3,91 & 0,92 & 0,23 \\
\hline $\begin{array}{l}\text { Organizo, analizo y uso la información a partir de herramientas digitales } \\
\text { de forma efectiva (archivos, carpetas, texto, tablas, imágenes, audio, } \\
\text { video, etc.) }\end{array}$ & 3,96 & 0,96 & 0,24 \\
\hline $\begin{array}{l}\text { Sintetizo la información seleccionada para la construcción y asimilación } \\
\text { del nuevo contenido }\end{array}$ & 3,71 & 0,92 & 0,25 \\
\hline
\end{tabular}




\begin{tabular}{|c|c|c|c|}
\hline $\begin{array}{l}\text { Devuelvo a la comunidad los contenidos creados utilizando herramientas } \\
\text { digitales (textos, tablas, imágenes, audio, video, etc.) }\end{array}$ & 2,95 & 1,25 & 0,42 \\
\hline $\begin{array}{l}\text { Hago la referencia correspondiente al utilizar contenidos protegidos por } \\
\text { copyright }\end{array}$ & 2,92 & 1,31 & 0,45 \\
\hline Seguridad / Ciudadanía digital & Media & DE & $\mathbf{C V}$ \\
\hline $\begin{array}{l}\text { Promuevo el uso seguro, responsable y legal de la información y de las } \\
\text { TIC }\end{array}$ & 3,39 & 1,19 & 0,35 \\
\hline $\begin{array}{l}\text { Conozco como se aplica la nueva normativa europea respecto a la } \\
\text { protección de datos General Data Protection Regulation (GDPT) }\end{array}$ & 2,09 & 1,18 & 0,57 \\
\hline Soy consciente de que tengo una identidad digital y sigo mi huella digital & 3,58 & 1,14 & 0,32 \\
\hline $\begin{array}{l}\text { Ejecuto y actualizo programas de seguridad en el ordenador que uso para } \\
\text { acceder a internet }\end{array}$ & 3,22 & 1,23 & 0,38 \\
\hline $\begin{array}{l}\text { Ejecuto y actualizo programas de seguridad en los dispositivos móviles } \\
\text { que uso para acceder a internet }\end{array}$ & 3,20 & 1,28 & 0,40 \\
\hline Creatividad e innovación & Media & DE & $\mathbf{C V}$ \\
\hline Aplico los conocimientos en TIC en la práctica profesional & 3,63 & 1,08 & 0,30 \\
\hline Desarrollo iniciativas con espíritu emprendedor en el uso de las TIC & 2,89 & 1,23 & 0,42 \\
\hline $\begin{array}{l}\text { Creo trabajos originales como medios de expresión personal o grupal } \\
\text { utilizando las TIC, como parte de mi aprendizaje permanente y reflexivo }\end{array}$ & 3,19 & 1,21 & 0,38 \\
\hline $\begin{array}{l}\text { Desarrollo experiencias que estimulen el pensamiento creativo e } \\
\text { innovador }\end{array}$ & 3,14 & 1,19 & 0,38 \\
\hline $\begin{array}{l}\text { Integro herramientas y recursos digitales para promover la capacidad de } \\
\text { aprendizaje y la creatividad }\end{array}$ & 3,24 & 1,17 & 0,36 \\
\hline Me adapto a nuevas situaciones y entornos tecnológicos & 4,03 & 0,88 & 0,22 \\
\hline
\end{tabular}

Por otra parte, en el cuestionario se preguntó a cada participante por sus competencias genéricas antes y durante el confinamiento por el COVID-19 y, como son valoraciones del mismo individuo, se realizaron contrastes de diferencias de medias para variables dependientes restando al valor "durante" el valor "antes". Además, se han buscado diferencias en las distintas habilidades en función de ser estudiante de primer curso o no y por sexo. En este caso, al tratarse de grupos de individuos diferentes, las muestras son independientes, por lo que se han realizado contrastes de diferencias de medias, con un contraste previo de la $\mathrm{F}$ para determinar si las varianzas de los dos grupos son iguales o no, y en función de ello elegir el estadístico $t$ correspondiente. En los resultados presentados a continuación, solo se han tenido en cuenta las competencias que muestran significación estadística en relación a estas variables.

\subsection{Resultados para DURANTE - ANTES del COVID-19}

El confinamiento debido a la pandemia generada por el COVID-19 pensamos que habría cambiado, además de los hábitos de la vida diaria de las personas, las competencias digitales de los estudiantes, al tener su docencia de manera telemática en lugar de presencial en las aulas. Éstas pasaron de un día para otro de ser en un centro de educación con profesores y compañeros pudiendo intercambiar conocimientos de forma interactiva, a tener que hacerlo cada uno en su casa con otro tipo de recursos y de manera virtual. Como se puede apreciar en la Tabla 3 esta creencia se ha visto ratificada claramente, pues en todas las competencias digitales por las que se preguntó acerca de su valoración antes y durante el confinamiento, la valoración es muy superior en el segundo caso. Las mayores diferencias se han detectado en el "Uso de la tecnología y herramientas digitales ha mejorado tu día a día" y en el "Trabajo en equipo virtual". Por contra, está diferencia, aunque estadísticamente significativa, es menor en el caso de la "Búsqueda de información online", seguramente debido a que este tipo de actividad ya era muy utilizada con anterioridad, de hecho, es la competencia más valora de todas las propuestas. 
Tabla 3. Contraste de diferencia de medias para DURANTE - ANTES

\begin{tabular}{lccrc}
\hline \multicolumn{1}{c}{ Competencia digital } & $\begin{array}{c}\text { Media } \\
\text { Durante }\end{array}$ & $\begin{array}{c}\text { Media } \\
\text { Antes }\end{array}$ & T & p-valor \\
\hline $\begin{array}{l}\text { El uso de la tecnología y herramientas digitales } \\
\text { ha mejorado tu día a día }\end{array}$ & 4,25 & 3,43 & 17,024 & $0,000^{* * *}$ \\
\hline $\begin{array}{l}\text { Comunicación } \\
\text { Trabajo en equipo virtual }\end{array}$ & 4,03 & 3,62 & 8,526 & $0,000^{* * *}$ \\
\hline $\begin{array}{l}\text { Búsqueda de información online } \\
\text { Herramientas ofimáticas (Excel, Word, ppt,...) }\end{array}$ & 4,00 & 3,16 & 14,283 & $0,000^{* * *}$ \\
$\begin{array}{l}\text { para tratar la información } \\
\begin{array}{l}\text { Ejecuto y actualizo programas de seguridad en } \\
\text { mis dispositivos }\end{array}\end{array}$ & 3,17 & 4,01 & 4,574 & $0,000^{* * *}$ \\
$\begin{array}{l}\text { Autoaprendizaje } \\
\text { * Significativo al 10\%, ** Significativo al 5\%,*** Significativo al 1\%. }\end{array}$ & 3,88 & 3,58 & 7,402 & $0,000^{* * *}$ \\
\hline
\end{tabular}

\subsection{Resultados para el primer curso}

Respecto a la situación creada por el COVID-19, los alumnos de Primero tienen una percepción significativamente menor que los de cursos superiores, acerca de que el uso de la tecnología y herramientas digitales ha mejorado su día a día durante el periodo del confinamiento. Antes del COVID-19, mostraban ya mayores capacidades de trabajo en equipo virtual y, tanto antes como durante el confinamiento, también eran más diestros manejando "Herramientas ofimáticas como Excel, Word, etc.", que el resto de los participantes en el estudio. Los de Primero son nativos digitales, están acostumbrados a utilizar el lenguaje digital de juegos por ordenador, video e Internet (Prensky, 2010), además tienen la necesidad de estar conectados permanentemente y de la inmediatez (Arias-Oliva, Torres-Coronas y Yalez-Luna, 2014), como ya formaba parte de su día a día quizá no notan tanta mejoría para su vida, aunque si han mejorado sus destrezas generales.

Los alumnos de Primer curso califican más alto que el resto de sus compañeros, sus habilidades en una competencia de alfabetización básica como es el "Uso de herramientas ofimáticas (Excel, Word, etc.)"; en una competencia colaborativa, como es la "Creación de equipos de trabajo multidisciplinares", y en "Referenciar los contenidos protegidos por copyright" cuando los utilizan. Donde destacan especialmente es en las competencias relacionadas con la creatividad e innovación, concretamente en cuatro de ellas: "Aplicar los conocimientos TIC en la práctica profesional", "Crear trabajos originales como medios de expresión con las TIC", "Desarrollar experiencias creativas e innovadoras" e "Integrar los recursos digitales en la mejora de sus capacidades creativas y de aprendizaje" (Ver Tabla 4). Esta valoración positiva en los alumnos de primer curso respalda la revisión de Fonseca et al. (2017), quienes señalan que el esfuerzo por ir incluyendo progresivamente más herramientas digitales en la enseñanza conforme avanza el alumnado desde la educación prescolar, primaria y secundaria donde utilizan dispositivos móviles y tabletas en el uso educativo a través de prácticas colaborativas que complementan su uso social, ayuda a que los estudiantes sean expertos en el uso de aplicaciones de ordenador y sistemas de trabajo colaborativo.

En cambio, los estudiantes de primer curso muestran menor destreza que los demás en la utilización de algunas herramientas de comunicación y colaboración, como los "Recursos en línea como Slideshare, Youtube, Flyckr, Google Video, etc."; en una cuestión importante de seguridad, como el hecho de "Tener consciencia de su identidad digital", y en dos elementos clave sobre el acceso y uso de la información: la "Organización efectiva de la misma con las herramientas digitales" y la "Devolución a la comunidad de contenidos creados del mismo modo" (Ver Tabla 4). 
Tabla 4. Contraste de diferencia de medias para primer curso (Primero - No Primero)

\begin{tabular}{|c|c|c|c|c|}
\hline Competencia digital & $\mathbf{F}$ & p-valor & $\mathbf{T}$ & p-valor \\
\hline $\begin{array}{l}\text { El uso de la tecnología y herramientas digitales ha mejorado } \\
\text { tu día a día DURANTE el periodo del confinamiento }\end{array}$ & 0,744 & 0,389 & $-2,740$ & $0,006 * * *$ \\
\hline Trabajo en equipo virtual ANTES & 0,002 & 0,962 & 2,287 & $0,023^{* *}$ \\
\hline $\begin{array}{l}\text { Herramientas ofimáticas (Excel, Word, ppt,...) para tratar la } \\
\text { información ANTES }\end{array}$ & 4,437 & $0,036^{* *}$ & 4,462 & $0,000 * * *$ \\
\hline $\begin{array}{l}\text { Herramientas ofimáticas (Excel, Word, ppt,...) para tratar la } \\
\text { información DURANTE }\end{array}$ & 1,845 & 0,175 & 1,998 & $0,047 * *$ \\
\hline $\begin{array}{l}\text { Utilizo distintas herramientas ofimáticas para el tratamiento } \\
\text { de la información (Excel, Word, etc.) }\end{array}$ & 0,347 & 0,556 & 1,876 & $0,062^{*}$ \\
\hline $\begin{array}{l}\text { Utilizo recursos en línea como Slideshare, Youtube, Flyckr, } \\
\text { Google Video, etc., para compartir y publicar online } \\
\text { conocimientos con otras personas }\end{array}$ & 2,441 & 0,119 & $-2,409$ & $0,017 * *$ \\
\hline $\begin{array}{l}\text { Creo equipos de trabajo multidisciplinares para el } \\
\text { desarrollo de proyectos o la resolución de problemas }\end{array}$ & 2,362 & 0,125 & 2,193 & $0,029 * *$ \\
\hline $\begin{array}{l}\text { Organizo, analizo y uso la información a partir de } \\
\text { herramientas digitales de forma efectiva (archivos, } \\
\text { carpetas, texto, tablas, imágenes, audio, video, etc.) }\end{array}$ & 0,433 & 0,511 & $-2,330$ & $0,020 * *$ \\
\hline $\begin{array}{l}\text { Devuelvo a la comunidad los contenidos creados utilizando } \\
\text { herramientas digitales (textos, tablas, imágenes, audio, } \\
\text { video, etc.) }\end{array}$ & 0,370 & 0,543 & $-1,777$ & $0,076^{*}$ \\
\hline $\begin{array}{l}\text { Hago la referencia correspondiente al utilizar contenidos } \\
\text { protegidos por copyright }\end{array}$ & 4,988 & $0,026^{* *}$ & 2,115 & $0,035^{* *}$ \\
\hline $\begin{array}{l}\text { Conozco como se aplica la nueva normativa europea } \\
\text { respecto a la protección de datos General Data Protection } \\
\text { Regulation (GDPT) }\end{array}$ & 5,082 & $0,025 * *$ & 3,845 & $0,000^{* * *}$ \\
\hline $\begin{array}{l}\text { Soy consciente de que tengo una identidad digital y sigo mi } \\
\text { huella digital }\end{array}$ & 0,224 & 0,637 & $-2,488$ & $0,013 * *$ \\
\hline Aplico los conocimientos en TIC en la práctica profesional & 3,456 & $0,064 *$ & 1,754 & $0,081^{*}$ \\
\hline $\begin{array}{l}\text { Creo trabajos originales como medios de expresión } \\
\text { personal o grupal utilizando las TIC, como parte de mi } \\
\text { aprendizaje permanente y reflexivo }\end{array}$ & 1,582 & 0,209 & 2,606 & $0,010^{* * *}$ \\
\hline $\begin{array}{l}\text { Desarrollo experiencias que estimulen el pensamiento } \\
\text { creativo e innovador }\end{array}$ & 0,909 & 0,341 & 1,693 & $0,091^{*}$ \\
\hline $\begin{array}{l}\text { Integro herramientas y recursos digitales para promover la } \\
\text { capacidad de aprendizaje y la creatividad }\end{array}$ & 0,147 & 0,702 & 1,982 & $0,048 * *$ \\
\hline
\end{tabular}

* Significativo al 10\%, ** Significativo al 5\%, *** Significativo al 1\%.

\subsection{Resultados por sexo}

Basándonos en las percepciones de los estudiantes, cuando se comparan las competencias genéricas antes y durante el COVID-19, las mujeres valoran más que los hombres el "Trabajo en equipo virtual" y la "Búsqueda de información durante la pandemia", mientras que los hombres valoran más la "Ejecución y actualización de programas de seguridad en mis dispositivos antes del COVID-19" y el "Autoaprendizaje" tanto antes como durante la pandemia.

Por otro lado, los resultados ponen de manifiesto que las mujeres tienen mayor dominio que los hombres en las siguientes competencias digitales: el "Uso de varios tipos de sistemas operativos instalados en dispositivos móviles"; el "Uso de herramientas de comunicación online como blogs, foros y redes sociales; el uso de herramientas de colaboración”; al "Organizar la información en carpetas, tablas, ...”; "Devolver 
a la comunidad los contenidos creados utilizando herramientas digitales"; "Referenciar los contenidos utilizados protegidos por copyright"; y "Promover el uso seguro de las TIC" (Ver Tabla 5). Por tanto, las mujeres destacan en competencias de Alfabetización tecnológica, Comunicación y colaboración, de Acceso y uso de la información y de Seguridad y ciudadanía digital. Estudios previos también han demostrado que el género tiene un impacto significativo en el nivel de habilidades y conocimiento auto percibidos relacionados con la web (Gui, 2007; Hargittai y Hinnant, 2008; Liff y Shepherd, 2004).

Tabla 5. Contraste de diferencia de medias por sexo (Hombre-Mujer)

\begin{tabular}{|c|c|c|c|c|}
\hline Competencia digital & $\mathbf{F}$ & p-valor & $\mathbf{t}$ & p-valor \\
\hline $\begin{array}{l}\text { Ejecuto y actualizo programas de seguridad en mis } \\
\text { dispositivos ANTES }\end{array}$ & 0,249 & 0,618 & 1,683 & $0,093 *$ \\
\hline Autoaprendizaje ANTES & 0,651 & 0,420 & 3,059 & $0,002 * * *$ \\
\hline Trabajo en equipo virtual DURANTE & 0,000 & 0,992 & $-2,160$ & $0,031 * *$ \\
\hline Búsqueda de información online DURANTE & 1,181 & 0,278 & $-1,685$ & $0,093 *$ \\
\hline Autoaprendizaje DURANTE & 1,294 & 0,256 & 2,022 & $0,044 * *$ \\
\hline $\begin{array}{l}\text { Utilizo varios tipos de sistemas operativos instalados en } \\
\text { dispositivos móviles (Android, IOS, etc.) }\end{array}$ & 1,684 & 0,195 & $-1,747$ & $0,081 *$ \\
\hline $\begin{array}{l}\text { Utilizo herramientas de comunicación online como blogs, } \\
\text { foros, redes sociales, etc. }\end{array}$ & 0,484 & 0,487 & $-1,848$ & $0,065^{*}$ \\
\hline $\begin{array}{l}\text { Utilizo herramientas de colaboración con otras personas } \\
\text { creando y gestionando contenidos como calendarios } \\
\text { electrónicos, sistemas de gestión de proyectos, Dropbox, } \\
\text { One Drive, Google Drive, etc. }\end{array}$ & 0,636 & 0,426 & $-2,619$ & $0,009 * * *$ \\
\hline $\begin{array}{l}\text { Organizo, analizo y uso la información a partir de } \\
\text { herramientas digitales de forma efectiva (archivos, } \\
\text { carpetas, texto, tablas, imágenes, audio, video, etc.) }\end{array}$ & 6,586 & $0,011 * *$ & $-3,662$ & $0,000 * * *$ \\
\hline $\begin{array}{l}\text { Devuelvo a la comunidad los contenidos creados utilizando } \\
\text { herramientas digitales (textos, tablas, imágenes, audio, } \\
\text { video, etc.) }\end{array}$ & 3,962 & $0,047 * *$ & $-2,923$ & $0,004 * * *$ \\
\hline $\begin{array}{l}\text { Hago la referencia correspondiente al utilizar contenidos } \\
\text { protegidos por copyright }\end{array}$ & 2,120 & 0,146 & $-2,820$ & $0,005^{* * *}$ \\
\hline $\begin{array}{l}\text { Promuevo el uso seguro, responsable y legal de la } \\
\text { información y de las TIC }\end{array}$ & 0,221 & 0,638 & $-2,421$ & $0,016^{* *}$ \\
\hline
\end{tabular}

\section{Conclusiones}

Acorde con los resultados de autoevaluación de diagnóstico del nivel de competencias digitales, los estudiantes se perciben con un buen nivel de competencias digitales y tienen claro que la tecnología digital será clave en su futuro, en su carrera profesional.

En líneas generales, los estudiantes universitarios presentan un buen manejo de las herramientas ofimáticas, aunque muestran un déficit en tratamiento de imagen, audio o video digital. Probablemente se deba al uso de estas herramientas en diversas asignaturas a lo largo de la carrera, en cambio en estos grados se hace poco uso de tratamiento de imagen o video digital. Es una cuestión que debería mejorarse en la formación de los alumnos de estas carreras universitarias, porque el mercado laboral cada vez lo demanda más. Sugerimos mejorar la formación del profesorado en este campo y empezar a incorporar estas destrezas poco a poco en la parte práctica de algunas asignaturas probando la capacidad de autoaprendizaje de los alumnos. También muestran elevada percepción en la comunicación online, esto forma parte de su día a día, es su 
forma de comunicarse; mientras que probablemente la mayoría no han sentido todavía la necesidad de formar parte o crear una red profesional, competencia en la que tienen una baja percepción.

Las diferentes valoraciones percibidas entre estudiantes de primer curso y el resto nos indican que están en distintos niveles de aprendizaje y que probablemente utilizan de forma diferente las posibilidades que las nuevas tecnologías ponen a su alcance. Por tanto, y coincidiendo con estudios previos como el de Bennett y Maton (2010), a pesar del uso generalizado de la tecnología en la universidad y de las mismas oportunidades, las diferencias en la valoración en las competencias digitales ponen de manifiesto la importancia de la formación y el autoaprendizaje. Los cambios constantes en la tecnología y sus usos hacen que el aprendizaje continuo sea considerado una competencia digital en sí misma (Puentes Digitales, 2017) y, como señalan Rincón et al (2017) es necesario que los individuos aprendan a aprender, desaprender y reaprender. El hecho de que el 74,64\% de los estudiantes encuestados no haya realizado ningún curso online en competencias digitales pone de manifiesto que las competencias digitales se pueden adquirir a través de la enseñanza reglada (institutos, universidad) y a través del autoaprendizaje. Además, los estudiantes han tenido que adquirirlas "a la fuerza" para adaptarse a la nueva enseñanza digital impuesta por la pandemia provocada por el COVID-19, mientras que formarse en aspecto como seguridad, protección de dispositivos, etc. requiere de una formación específica que las universidades normalmente no ofrecen de manera reglada y los estudiantes tampoco realizan de manera autónoma al no ser conscientes de su importancia y "no servirles" para realizar sus estudios.

Por otra parte, se encuentran diferencias significativas entre las mujeres y los hombres, de manera que las primeras destacan en competencias relacionadas con las relaciones sociales, colaboración, análisis y tratamiento de la información y en las cuestiones relacionadas con la seguridad en las redes frente a la valoración de los hombres.

Los estudiantes utilizan las TIC disponibles adaptándolo a sus necesidades de cada momento, probablemente sea uno de los motivos por los que las competencias digitales genéricas han mejorado durante el confinamiento. Estamos acostumbrados a utilizar internet para buscar información, así lo corrobora el hecho de que la búsqueda de información online es la competencia más valorada tanto "antes" como "durante" la situación de confinamiento provocada por el COVID-19. En cambio, un desafío importante es inculcar la necesidad de proteger los dispositivos actualizando los programas de seguridad. La baja preocupación en este sentido se ha mantenido, incluso durante la pandemia. En el entorno actual se maneja una gran cantidad de datos personales a través de las redes y los ataques cibernéticos no dejan de crecer.

En resumen, hay que seguir avanzando en la necesidad de adaptar la enseñanza universitaria a las nuevas competencias exigidas por parte de las empresas en los futuros trabajadores, puesto que es una realidad la creciente necesidad de cualificaciones digitales en el lugar de trabajo. En esta misma línea, hay que incluir e integrar el uso de las TIC al servicio del proceso de enseñanza, reconociendo que el aprendizaje no sólo se da en la educación reglada.

Entre las limitaciones que plantea este estudio, se encuentran las derivadas de realizar un estudio estático en un momento concreto, circunstancia que no permite analizar la evolución en la valoración de las competencias digitales de los alumnos a lo largo de la formación recibida en la carrera. Para investigaciones futuras sería interesante analizar las competencias de estos estudiantes en años posteriores. 


\section{Referencias}

ARIAS-OLIVA, M., TORRES-CORONAS, T. y YÁLEZ-LUNA, J. C. (2014). "El desarrollo de competencias digitales en la educación superior” en Historia y Comunicación Social, vol. 19, nº especial enero, 355-366.

BENNETT, S. y MATON, K. (2010). "Beyond the 'digital natives' debate: Towards a more nuanced understanding of students' technology experiences” en Journal of Computer Assisted Learning, vol. 26, n 5, 321-331.

BURTON, P. (2019). The importance of digital Skills in the modern Workplace. $<$ https://www.skillsyouneed.com/rhubarb/digital-skills-modern-workplace.html> [Consulta: 26 de abril de 2021].

DEDE, C. (2010). "Comparing frameworks for 21st century skills" en Bellanca, J. y Brandt, R. 21st century skills Bloomington, IN: Solution Tree Press. 51-76.

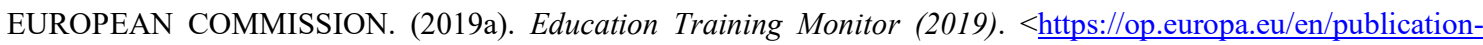
detail/-/publication/15d70dc3-e00e-11e9-9c4e-01aa75ed71a1/language-en/format-PDF/source-search> [Consulta: 29 de marzo de 2021].

EUROPEAN COMMISSION. (2019b). The Digital Competence Framework 2.0. $<$ https://ec.europa.eu/jrc/en/digcomp/digital-competence-framework> [Consulta: 29 de marzo de 2021].

FONSECA, D., REDONDO, E., VALLS, F. y VILLAGRASA, S. (2017). “Technological adaptation of the student to the educational density of the course. A case study: 3D architectural visualization" en Computers in Human Behavior, vol. 72, 599-611.

GARCÍA, J. V. y PÉREZ, M. C. (2008). "Espacio Europeo de Educación Superior, competencias profesionales y empleabilidad” en Revista Iberoamericana de Educación, vol. 46, nº 9, 1-12.

GUI, M. (2007). "Formal and substantial Internet information skills: the role of socio-demographic differences on the possession of different components of digital literacy" en First Monday, vol. 12, no 9.

GUI, M. y ARGENTIN, G. (2011). "Digital skills of internet natives: Different forms of digital literacy in a random sample of northern Italian high school students" en New Media \& Society, vol. 13, n 6, 963-980.

HARGITTAI, E. y HINNANT, A. (2008). “Digital inequality: differences in young adults' use of the Internet" en Communication Research, vol. 35, $\mathrm{n}^{\circ}$ 5, 602-621.

KISS, M. [EUROPEAN PARLIAMENTARY RESEARCH SERVICE]. (2017). Digital skills in the EU labor market. $<$ http://www.europarl.europa.eu/RegData/etudes/IDAN/2017/595889/EPRS IDA(2017)595889 EN.pdf> [Consulta: 27 de marzo de 2021].

LIFF, S. y SHEPHERD, A. (2004). “An evolving gender digital divide?” Oxford Internet Institute. Internet Issue Brief, 2, 1-17. <http://www.oii.ox.ac.uk/resources/publications/IB2all.pdf> [Consulta: 28 de marzo de 2021].

LION, C. (2013). Desarrollo de competencias digitales para portales de la región. $<$ https://uruguayeduca.anep.edu.uy/sites/default/files/2018-02/09-Desarrollo-de-Competencias-Digitales-paraPortales-de-la-Regi\%C3\%B3n\%20(1)\%20(1)(1).pdf> [Consulta: 27 de marzo de 2021].

MARTÍNEZ, H. (2009). "La integración de las TIC en instituciones educativas” en Caneiro, R., Toscano, J. C. y Díaz T. Los desafios de las TIC para el cambio educativo, 61-70. Madrid: Santillana.

PARLAMENTO EUROPEO Y CONSEJO DE LA UNIÓN EUROPEA. (2006). Recomendación del parlamento europeo y del consejo de 18 de diciembre de 2006 sobre las competencias clave para el aprendizaje permanente [2006/962/CE]. Diario Oficial de la Unión Europea de 30 de diciembre de 2006. <https://eur-lex.europa.eu/legalcontent/ES/TXT/PDF/?uri=CELEX:32006H0962\&from=ES $>$ [Consulta: 26 de marzo de 2021].

PRENSKY, M. (2010). Nativos e inmigrantes digitales. <https://www.marcprensky.com/writing/PrenskyNATIVOS\%20E\%20INMIGRANTES\%20DIGITALES\%20(SEK).pdf> [Consulta: 27 de marzo de 2021].

(c)) BY-NC-ND 2021, Universitat Politècnica de València

Congreso In-Red (2021) 
PUENTES DIGITALES. (2017). Nuevo mercado laboral: Competencias Digitales y empleabilidad. <https://puentesdigitales.com/2017/11/02/nuevo-mercado-laboral-competencias-digitales-y-empleabilidad/> [Consulta: 29 de marzo de 2021].

RINCÓN, A. G., ZEPEDA, H. H., PRIETO, P., MÉNDEZ, M. E. y GONZÁLEZ, A. (2017). “Las competencias TIC en Educación. Descripción de las competencias digitales en los alumnos de nuevo ingreso" en Revista Electrónica sobre Tecnología, Educación y Sociedad, vol.4, nº7.

SCOPEO. (2011). M-learning en España, Portugal y América Latina. Noviembre de 2011. Monográfico SCOPEO, $n^{\circ}$ 3. Salamanca: Servicios de publicaciones de la Universidad de Salamanca. <http://scopeo.usal.es/wpcontent/uploads/2013/04/scopeom003.pdf> [Consulta 27 de marzo de 2021].

TORRES-CORONAS, T. y VIDAL-BLASCO M.A. (2015). "Percepción de estudiantes y empleadores sobre el desarrollo de competencias digitales en la Educación Superior” en Revista de Educación, vol. 367, 63-90. 